\title{
EDUCACIÓN, JUECES Y CONSTITUCIÓN, 1978-2018 (I). LA EDUCACIÓN SEPARADA POR SEXOS
}

\author{
Education, judiciary and Constitution, 1978-2018 (I). \\ The single-sex schooling
}

\section{Antonio Viñao ${ }^{\alpha}$}

Fecha de recepción: 05/09/2019 • Fecha de aceptación: 04/10/2019

Resumen. La educación separada por sexos constituyó uno de los cinco puntos considerados en la sentencia del Tribunal Constitucional (TC) de 10 de abril de 2018, desestimando el recurso de constitucionalidad interpuesto por más de 50 diputados del Partido Socialista contra la Ley Orgánica para la Mejora de la Calidad Educativa de 10 de diciembre de 2013. La lectura de dicha sentencia muestra las posiciones ideológicamente enfrentadas entre la opinión mayoritaria del TC y los votos particulares emitidos en relación con la naturaleza discriminadora o no de dicho modelo educativo y, por tanto, sobre su inconstitucionalidad o constitucionalidad, así como sobre la existencia y contenido de un ideario educativo constitucional, entre otros aspectos. En este ensayo se comentan y contextualizan tanto la sentencia como los votos particulares.

Palabras clave: Educación separada por sexos; Tribunal Constitucional; Constitución española de 1978; Conciertos educativos.

Abstract. Single sex schooling was one of the five points considered in the court ruling established by the Constitutional Court (CC) on 18 April 2018, in a decision rejecting the appeal presented by over 50 Socialist Party MPs against the Organic Law for the Improvement of Educational Quality of 10 December 2013. A close reading of this ruling reveals the ideological confrontation between the majority view represented by the CC and the dissenting view expressed about whether or not this educational model was discriminatory and whether or not such a model is constitutional. Other elements include a discussion concerning the existence and content of a

\footnotetext{
a Departamento de Teoría e Historia de la Educación. Facultad de Educación. Campus universitario de Espinardo, 30100 Murcia. España. avinao@um.es.
} 
constitutional educational ideology. In this essay both the ruling and the dissenting votes are commented upon and contextualized.

Keywords: Single sex schooling; Constitutional Court; Spanish Constitution of 1978; Educational subsidies to independent schools.

Vendrán más años malos y nos harán más ciegos; vendrán más años ciegos y nos harán más malos. ${ }^{1}$

\section{ORIGEN Y NATURALEZA DEL ENSAYO²}

El título original de este texto era «Educación, jueces y Constitución (1978-2018). Ensayo sobre la ceguera». La extensión que estaba tomando conforme iba cobrando vida me indujo a dividirlo, de momento, en dos partes, indicando en el subtítulo el tema sobre el que gira cada una de ellas: la educación diferenciada o separada por sexos y la vigencia en España de la Convención sobre los derechos del niño de 20 de noviembre de 1989 o, más bien, de los derechos formativos, educativos y mentales de los menores. El origen del ensayo se halla en la perplejidad, y consiguiente interés, producida por la lectura de la sentencia del Tribunal Constitucional (TC) de 10 de abril de 2018, desestimando el recurso de constitucionalidad interpuesto por más de 50 diputados del Partido Socialista (PSOE) contra la Ley Orgánica para la Mejora de la Calidad Educativa (LOMCE) de 10 de diciembre de 2013. La perplejidad y el interés procedían, en principio, del hecho de que cinco de los doce miembros del TC habían emitido cuatro votos particulares —uno de ellos

\footnotetext{
1 Rafael Sánchez Ferlosio, Vendrán más años malos y nos harán más ciegos (Barcelona: Círculo de Lectores, 1995), 5.

2 La redacción de este ensayo - por asignarle una naturaleza específica en una taxonomía de textos posibles - ha estado precedida de una serie de conferencias, seminarios o charlas donde en los dos últimos años he ido desgranando y ordenando, ante diversos públicos, lo que ahora se expone por escrito: «Educación, jueces y Constitución. ¿Una cuestión interpretativa o ideológica?», Jornadas sobre Una educación para el siglo XXI. Miradas desde las ciencias y las artes, Murcia, 17 de enero de 2019; «Coeducación e igualdad de género en la sentencia del Tribunal Constitucional (10/4/2018) sobre la LOMCE», Facultad de Educación de la Universidad Complutense, 30 de abril de 2019; y «Educación, jueces y Constitución: ¿interpretación o ideología», Facultad de Educación de la Universidad de Valencia, 15 de mayo de 2019. Se ha beneficiado, pues, de los comentarios y debates que se produjeron en dichas exposiciones orales, así como de las observaciones formuladas por los informantes o evaluadores del artículo aunque, como es obvio, las opiniones y juicios expresados en el mismo corresponden solo al autor.
} 
suscrito por dos jueces- en los que se disentía en mayor o menor medida del voto mayoritario suscrito por los otros siete miembros del alto tribunal. Una división - siete/cinco-y un número de votos particulares que contrastaba con la unanimidad con que el TC resolvió en sentencia de 27 de junio de 1985 el recurso interpuesto contra la Ley Orgánica reguladora del Derecho a la Educación (LODE) de 3 de julio de 1985, e incluso con la sentencia emitida por este mismo tribunal el 13 de febrero de 1981 al resolver el recurso interpuesto contra la Ley Orgánica de 13 de julio de 1980 por la que se regulaba el Estatuto de Centros Escolares (LOECE). Una sentencia este última, es cierto, con dos votos particulares parcialmente discrepantes; uno formulado por el magistrado Francisco Tomás y Valiente y suscrito por otros tres miembros de los 11 que componían el TC, y otro formulado por otros dos magistrados, pero ambos redactados, en sus formas y expresiones, con un talante muy diferente al de los votos particulares emitidos con motivo de la sentencia de 2018 sobre la LOMCE.

En efecto, conforme iba leyendo esta última sentencia, sobre todo tres de los cuatro votos particulares, mi perplejidad e interés se acrecentaban. Más allá de las divergencias y argumentos jurídicos, y de la admisible discrepancia justificativa del desacuerdo con la opinión mayoritaria adoptada como sentencia definitiva, hallaba expresiones inusuales de cierta dureza crítica y claro signo ideológico-interpretativo. En síntesis, cuatro de los discrepantes se opusieron, sin ambages, a la sentencia dictada por entender que la concepción ideológica que subyace, en relación con la consideración como constitucional de los párrafos $2^{\circ}$ y $3^{\circ}$ del artículo 84.3 de la LOMCE —en los que, al regular el sistema de admisión del alumnado en los centros docentes, se declara no discriminatoria la separación o educación diferenciada por sexos, sin que en ningún caso dicha educación diferenciada pueda implicar un trato menos favorable o desventaja a la hora de suscribir conciertos con las administraciones educativas o en cualquier otro aspecto-, corresponde a una época no ya preconstitucional sino anterior a la Ley General de Educación (LGE) de 1970, y que, tanto ideológica como jurídicamente, a quienes la suscriben -me permito expresiones coloquiales que no figuran en la sentencia- se les paró el reloj en dichos años; es decir, en los años sesenta del siglo XX, en pleno franquismo.

Volveré más adelante sobre esta cuestión. En estos párrafos de índole introductoria solo me resta aclarar, por si no fuera ya evidente, que no 
pretendo elaborar un texto de naturaleza exclusiva o fundamentalmente jurídica. De ahí que a quienes se desenvuelven en dicho ámbito les pueda parecer en ocasiones inconsistente o superficial. Lo hago por varias razones. Una de ellas es mi experiencia como jurista: la norma, el derecho positivo, puede ser y es a menudo retorcido en su interpretación, en función de la ideología y/o intereses de quien lo interpreta, hasta el punto de hacerle decir lo contrario, si es necesario, de lo que parece que dice. Esta apreciación no debe entenderse necesariamente en sentido negativo. Como en uno de los votos particulares de la sentencia sobre la LOMCE se afirma —apoyándose en la sentencia 198/2012 del mismo TC-, la Constitución debe ser interpretada como un «árbol vivo ${ }^{3}$ si es que, añado, se quiere que perdure. Ha de adaptarse, mediante la interpretación, a los cambios sociales, culturales y mentales sin tener que recurrir al rígido procedimiento formalmente establecido para su reforma. Pondré solo un ejemplo: si los "padres» de la Constitución de 1978, de cualquier ideología, hubieran pensado que el párrafo $1^{\circ}$ del artículo $32-« E l$ hombre y la mujer tienen derecho a contraer matrimonio con plena igualdad jurídica»— podía ser interpretado algún día en el sentido de que con dicha redacción se admitía el matrimonio entre personas del mismo sexo, no creo que nadie albergue la menor duda de que dicho párrafo se habría redactado de otro modo. Desde luego, no fue esa la mens legislatoris a la que tanto gustan recurrir, cuando interesa, los intérpretes del derecho positivo. La Constitución es, pues, un «árbol vivo» susceptible de muy diversas interpretaciones, en bastantes ocasiones encontradas. Que predomine una u otra dependerá no solo de los cambios sociales, culturales y mentales operados en el tiempo, sino también, en relación con ellos, de la formación, mentalidad e ideología de quienes han de interpretarla y aplicarla; es decir, de los jueces y, junto a ellos, de los expertos o tratadistas, sobre todo, en este caso, de derecho constitucional, administrativo o eclesiástico del Estado.

Tal es, además, mi experiencia directa o indirecta con la judicatura: hay jueces para todo y, según quien te toque en suerte, puede haber, o no haber, una notable diferencia tanto en las medidas adoptadas durante el

\footnotetext{
${ }^{3}$ Sentencia 31/2018, de 10 de abril de 2018, BOE de 22 de mayo de 2018, 53630.
} 
proceso como en la resolución o sentencia dictada. ${ }^{4}$ En otro caso, no tendría explicación el interés de los partidos políticos y grupos de interés o presión por controlar no solo el acceso a la judicatura, sino también la carrera judicial y los nombramientos del Tribunal Supremo y del Constitucional, por no aludir a los tribunales supremos de cada Comunidad Autónoma o incluso, si fuera necesario, los juzgados de primera instancia. Como tampoco la tendría el que determinadas denuncias o escritos se presenten en un juzgado u otro, o cuando se tiene noticia cierta de que el juez de turno es más favorable o cercano ideológica, profesional o económicamente a las pretensiones de quienes las suscriben. En este punto, solo adelanto la hipótesis —el caso analizado es un buen ejemplo de ello- de que los intensos y rápidos cambios sociales y culturales acaecidos en la sociedad española en las tres últimas décadas no han llevado consigo un cambio similar en la mentalidad y concepciones del mundo y de la vida —eso que algunos llaman cosmovisión- de buena parte de la judicatura y tratadistas de estos temas.

Otra razón explicativa del enfoque, estilo y modo de escribir adoptados en este texto es que mis intereses académico-intelectuales se mueven más en el campo de la educación y del análisis social, histórico e ideológico-político que del derecho. De ahí que mi formación jurídica esté, cuanto lo está, más al servicio de este tipo de consideraciones que de la búsqueda de una supuesta interpretación «correcta» del derecho positivo y, menos aún, de la Constitución. No busco sentar «doctrina», solo esclarecer y entender tanto las cuestiones ideológico-interpretativas que subyacen en las diferentes interpretaciones judiciales o de los tratadistas sobre el tratamiento constitucional de la educación, como su evolución en el tiempo. En otras palabras, frente a la actitud formal -no real, al menos de modo explícito-, aparentemente neutral, de una amplia mayoría de tratadistas y magistrados que hacen abstracción, en sus

\footnotetext{
${ }^{4}$ Una afirmación de este tipo puede parecer excesiva. Baste citar, entre otros ejemplos conocidos de lo que se ha llamado la «judicialización de la política» o «politización de la justicia», el del ácido bórico con motivo de la instrucción del juicio sobre los atentados del 11 de marzo de 2004: donde un juez, en unos informes policiales, veía indicios de delito en unos policías y exculpaba a otros, la juez a la que posteriormente se asignó la investigación vio indicios de delito en quienes antes habían sido exculpados y exculpaba a quienes antes habían sido imputados. Según que se aceptara un criterio u otro quedaba, o no, en entredicho la versión gubernamental sobre la intervención de ETA en dichos atentados. Al final la causa fue archivada sin hallar culpabilidad alguna: https://es.wikipedia.org/ wiki/Caso_del_informe_sobre_el_\%C3\%A1cido_b\%C3\%B3rico\#Fase_judicial (consultado el 03-092019). Los ejemplos pueden multiplicarse.
} 
consideraciones e interpretaciones jurídicas, de los contextos sociales en los que se aplican las normas - aquí habría que recordar el aforismo summum ius, summa iniuria-, este ensayo pretende confrontar el derecho positivo con la realidad, así como, hasta donde es posible, con las ideologías e intereses materiales y corporativos de quienes lo interpretan. Un solo ejemplo bastará para entenderlo. El derecho a la libre elección de centro docente es, como se verá, un derecho indirectamente constitucionalizado para un buen número de tratadistas y jueces —así se considera en la sentencia de 2018 sobre la LOMCE-. Las consecuencias sociales de su aplicación en un contexto determinado - como sucede con los conciertos educativos o sucedería con la implantación del cheque escolar - no se tienen en cuenta. Sin embargo, el hecho de que dicho derecho - que, por cierto, ya figuraba en el artículo 5 del Fuero de los Españoles de 17 de julio de 1945, y que asimismo figura en el programa de un partido de ultraderecha como Vox - sea el origen, por sí mismo, de desigualdades socio-educativas no parece ser relevante. Como tampoco lo es que en la práctica, aplicado en toda su pureza, no pase de ser un simple eufemismo de la libertad de (s)elección del alumnado por aquellos centros docentes en los que la demanda supera a la oferta. Se considera que todo ello no guarda relación alguna con el principio o valor de igualdad recogido en los artículos 1.1 y 9.2 CE ni con «el pleno desarrollo de la personalidad humana» como finalidad del derecho a la educación (art. 27.2 CE). Así, no es extraño encontrar tratadistas constitucionalmente sensibles ante aquellas normas que originan desigualdades entre las familias según que vivan en unas u otras comunidades autónomas a consecuencia de la distinta aplicación de la legislación educativa - por ejemplo, en relación con la concesión o denegación del concierto a centros docentes con educación separada por sexos-, que, sin embargo, muestran una clamorosa ceguera ante las evidentes desigualdades producidas por la política de conciertos $-\mathrm{O}$ ante realidades como la «masiva, consentida y generalizada [...] práctica de cobros por parte de los centros concertados», y la "práctica imposibilidad de fiscalización de la correcta aplicación de las normas de admisión, especialmente en los centros concertados $»^{5}$-, o ante las desigualdades y guetos

\footnotetext{
5 Lorenzo Cotino Hueso, «El derecho a la educación», en Lecciones sobre Estado Social y Derechos Sociales, eds. Albert Fernández Noguera y Adoración Guamán Hernández (Valencia: Tirant lo Blanch, 2014), 428 y 439, respectivamente.
} 
educativos que produciría la constitucional, a su juicio, implantación del cheque escolar, como indican las evidencias empíricas obtenidas allí donde se ha seguido este modelo de financiación de la educación. Tampoco extrañará, por tanto, a quien se adentre en la lectura de la literatura jurídica y judicial sobre este, y otros temas, que la gran mayoría de quienes interpretan la Constitución desde perspectivas llamémosles conservadoras - por poner el acento más en la libertad de enseñanza entendida exclusivamente como libertad de creación de centros docentes y, sobre todo, en el derecho de los padres a que sus hijos reciban una educación conforme a sus convicciones religiosas y morales como fundamento de la libre elección de centro docente- pertenezcan o sean afines a grupos católico-conservadores o trabajen en universidades privadas de idéntico signo ideológico. Eso no les da la razón ni se la quita, pero sí constituye un dato - el importante peso y claro activismo del lobby católico-conservador tanto en la judicatura como entre los tratadistas - que el analista social debe tener en cuenta si es que pretende conocer los intereses de todo tipo que subyacen en unas u otras interpretaciones.

\section{CONSIDERACIONES GENERALES SOBRE LA SENTENCIA DE 10 DE ABRIL DE 2018 Y EL ALCANCE DEL ENSAYO}

Aunque en ocasiones aludamos a otras sentencias anteriores sobre cuestiones educativas del TC, u otros tribunales, este texto solo considerará aquellos temas tratados en la sentencia mayoritaria - la que vale, la que sienta doctrina jurisprudencial- del TC de 10 de abril de 2018 sobre la LOMCE — con su complementaria sentencia, asimismo del TC, de 5 de julio de 2018-, o en sus votos particulares, que muestran la existencia en el seno del alto tribunal de dos concepciones o interpretaciones radicalmente opuestas de la Constitución en materia de enseñanza —al igual que en la arena política hay al menos dos modelos contrapuestos de sistema educativo, con toda una amplia gama de situaciones intermedias-, y que, de ellas, ha prevalecido la mayoritaria como podía haber podido prevalecer la minoritaria si la composición del TC hubiera sido otra. Aunque, todo hay que decirlo, estimo que la interpretación prevalente en ambas sentencias, de índole ideológicamente conservadora, se corresponde con la que asimismo predomina $-\mathrm{o}$ ha sido claramente predominante hasta hace poco-, en el resto de la magistratura y, sobre 
todo, entre buena parte de los tratadistas y comentaristas del texto constitucional.

Descartado, pues, el intento de analizar la evolución de la doctrina del TC en materia de enseñanza —en 1985 Embid Irujo recogía ya once sentencias sobre el tema- 6 desde la primera sentencia, la de 13 de febrero de 1981 sobre la mencionada LOECE, hasta la de 10 de abril de 2018 sobre la LOMCE, tengo también que advertir que no pretendo, en este momento, llevar a cabo un análisis exhaustivo de todas las cuestiones tratadas en esta última. Me limitaré a aquellas que, además de mostrar esa amplia divergencia interpretativa, ofrecen, por un lado, aspectos novedosos en relación con sentencias anteriores o sus votos particulares - por ejemplo, la limitación que en la sentencia se establece al poder legislativo al declarar inconstitucional cualquier disposición legal que en el futuro excluya de los conciertos educativos a aquellos centros docentes de educación separada por sexos-, y, por otro, muestran en el alto tribunal, la judicatura y los tratadistas en general una clara «ceguera» ante la existencia, por imperativo constitucional, de normas internacionales vigentes en el derecho positivo español tras la promulgación de la Constitución de 1978.

Cinco son las cuestiones objeto del recurso: (a) la ya indicada sobre la constitucionalidad de la educación diferenciada por sexos y de los conciertos a los centros docentes que opten por este modelo educativo (el artículo 84.3 de la LOMCE); (b) las restricciones impuestas a los derechos de los padres y madres, el profesorado y el alumnado a intervenir en el control y gestión de los centros sostenidos con fondos públicos, en relación con los que se le reconocían en la legislación anterior (artículos 127 y 132 y apartados $3^{\circ}, 4^{\circ}$ y $5^{\circ}$ de la disposición final segunda); (c) la configuración de las disciplinas de Valores culturales cívicos o Valores éticos, en las enseñanzas primaria y secundaria y el bachillerato, como asignaturas alternativas de la de Religión confesional (artículos 18, 24 y 25); (d) la separación del alumnado por itinerarios en la educación secundaria obligatoria (artículos 27, 28, 30, 31 y 42); y (e) el régimen jurídico de la selección de alumnado por su rendimiento académico en los centros públicos o concertados (artículo 84.2).

\footnotetext{
6 Antonio Embid Irujo, «Prólogo», en Legislación sobre enseñanza. Normas generales, EGB, FP y BUP (Madrid: Tecnos, 1985), 21-22.
} 
De todas las cuestiones expuestas limitaremos nuestro análisis en este momento a la primera de ellas, la relativa a la educación separada por sexos, dejando para una segunda parte de este ensayo, por su extensión, otra que sobrevuela toda la sentencia y los votos particulares: la generalizada ceguera ideológica que se padece ante la vigencia de la Convención de los derechos del niño de 1989. Todo ello tras llevar a cabo una síntesis general de la interpretación prevalente en la judicatura y los tratadistas sobre aquellos artículos que en la Constitución tratan cuestiones educativas —en especial, pero no solo, el artículo 27- o afectan, por su naturaleza fundamental y más amplia a las mismas, sin que dicha limitación temática sea un obstáculo —-más bien será un pretexto—para abordar otros asuntos o puntos político-educativos a debatir en relación con las interpretaciones judiciales que usualmente se hacen del texto constitucional.

\section{FUNDAMENTACIÓN CONSTITUCIONAL DE LAS SENTENCIAS DEL TC Y DEL TRIBUNAL SUPREMO EN MATERIA DE EDUCACIÓN}

¿Cuál es la interpretación o doctrina constitucional que se viene manteniendo de modo generalizado, sostenido y reforzado en el tiempo, tanto en el TC como en el Tribunal Supremo (TS), sobre las libertades y derechos en materia de enseñanza, y en la que se fundamentan sus sentencias? ${ }^{7}$ ¿Cuáles son su estructura, criterios y argumentaciones básicas?

En síntesis, se haga o no explícito, el modelo educativo, el arco de bóveda que da forma tanto al sistema educativo español como al derecho a la educación como derecho prestacional (art. 27.1 CE) según la interpretación del texto constitucional que prevalece entre la magistratura, está sostenido por dos pilares: la libertad de enseñanza (art. 27.1 $\mathrm{CE}$ ) entendida fundamental y exclusivamente como libertad de creación de centros docentes (art. 27.6 CE) y, sobre todo - hasta el punto de que

\footnotetext{
${ }^{7}$ En relación con la interpretación dominante en el TS, al menos hasta los años finales del siglo pasado, véase Gerardo Ruiz-Rico Ruiz, «El derecho a la educación en las sentencias del Tribunal Supremo», en Estudios de Derecho Público. Homenaje a Juan José Ruiz-Rico (Madrid: Tecnos, 1997), vol. I, 837-861, y sobre la cuestión de la educación separada por sexos y los conciertos educativos hasta fechas más recientes, Fernando Centenera Sánchez-Seco, «Educación diferenciada y conciertos educativos: algunas consideraciones a partir de la jurisprudencia del Tribunal Supremo de los últimos años», Anuario de Derecho Eclesiástico del Estado XXX (2014): 767-796.
} 
en ocasiones es el que exige o pone a su servicio la libertad anterior-, el derecho de los padres a que sus hijos reciban la educación religiosa y moral acorde con sus convicciones (art. 27.3 CE). Y, como exigencia de ambos pilares: (a) el derecho al concierto o ayuda pública a todo centro privado que lo solicite, al menos en la enseñanza básica, y cumpla los requisitos que la ley establece (arts. 27.4 y $27.9 \mathrm{CE}$ ), siempre y cuando, como se verá, estos requisitos no impidan o dificulten el pluralismo intercentros, es decir, la libertad y, de nuevo sobre todo, el derecho parental antedicho; (b) el derecho de los centros privados, concertados o no, a tener un ideario propio - reconocido, de modo expreso en la mencionada sentencia del TC de 1981 sobre la LOECE — con el fin, de nuevo, de que las familias puedan optar por uno u otro ideario; y (c) la libertad de elección de centro docente. Una libertad, esta última, no expresamente reconocida por la Constitución, pero que, según dicha argumentación, se deduce, como exigencia ineludible, de las libertades y derechos anteriores. ${ }^{8}$ Como se argumenta en la sentencia de 10 de abril de 2018 sobre la LOMCE,

el ideario ha de ser considerado en gran medida, aunque no solo, como punto de convergencia que posibilita el ejercicio del derecho de creación de centros y el derecho de los padres a elegir el tipo de educación que desean para sus hijos, poniendo en conexión oferta y demanda educativa. ${ }^{9}$

O, como más adelante se dice, transcribiendo un párrafo de la sentencia del TC sobre la LODE de 27 de junio de 1985,

el derecho de los padres a decidir la formación religiosa y moral que sus hijos han de recibir [...] es distinto del derecho a elegir centro docente que enuncia el artículo 13.3 del Pacto Internacional de Derechos Económicos, Sociales y Culturales, aunque es obvio que la elección de centro docente sea un modo de elegir una determinada formación religiosa y moral.

\footnotetext{
${ }^{8}$ La constitucionalización indirecta o implícita de la libertad de elección de centro docente ha sido mantenida por diversos tratadistas; por ejemplo, por Alfonso Fernández-Miranda Campoamor y Ángel J. Sánchez Navarro, "Artículo 27. Enseñanza», en Comentarios a la Constitución española de 1978. Tomo III. Artículos 24 a 38, dir. Óscar Alzaga Villamil (Madrid: EDERSA, 1996), 205, y María Calvo Charro, «La libertad de elección de centro docente. Historia de la conculcación de un derecho fundamental», Asamblea: Revista de Parlamentaria de la Asamblea de Madrid 14 (2006): 81-100.
}

9 Sentencia 31/2018, de 10 de abril de 2018, 5370-5371. 
Esa «falta de identidad», continua la sentencia, «no impide una indudable conexión entre el derecho al ideario», por parte de los centros docentes, y el «derecho de los padres a la elección de centro escolar». Un derecho-libertad que, de este modo, queda configurado como constitucional. ${ }^{10}$

Por supuesto, tanto la opinión mayoritaria del TC — la que posee valor jurisprudencial - como la de aquellos tratadistas que la apoyan, no ignoran la existencia - aunque se muestren renuentes a utilizar tal expresión- de un ideario educativo constitucional recogido, de modo específico, en el art. 27.2 CE al definir como «objeto» o fin de la educación «el pleno desarrollo de la personalidad humana en el respeto a los principios democráticos de convivencia y a los derechos y libertades fundamentales», algo ya formulado en el voto particular emitido por Francisco Tomás y Valiente, al que se adhirieron otros tres magistrados, en la STC 189/80, de 13 de febrero de 1981, conectando, además, dicho artículo con el 10.1 CE en el que asimismo se afirma que «el libre desarrollo de la personalidad» constituye uno de los fundamentos del «orden político y de la paz social». ${ }^{11}$ Ambos artículos, entre otros, hacen que, en

\footnotetext{
10 Sentencia 31/2018, de 10 de abril de 2018, 5372. Una síntesis de dicha interpretación constitucional, resumiendo y recogiendo lo esencial de la sentencia, puede verse en la posterior sentencia del TC 74/2018, de 5 de julio de 2018 (BOE 6 de agosto de 2018), 79301-79302, resolviendo favorablemente el recurso de amparo interpuesto por la asociación de padres del colegio Torrevelo, del Grupo Educativo Fomento, contra las sucesivas resoluciones administrativas y judiciales, dictadas entre 2009 y 2012, por las que se denegaba el acceso y renovación del concierto en aplicación de las disposiciones de la LOE de 2006 que, según la administración y los distintos tribunales de justicia —hasta llegar al Tribunal Supremo--, permitían a la administración educativa de las comunidades autónomas denegarlo a aquellos centros docentes que optaren por la educación diferenciada por sexos. Sorprende al desconocedor de los intríngulis y peculiaridades del sistema judicial español el hecho de que el ponente de la sentencia fuera un magistrado, Andrés Ollero Tassara, miembro notorio y público del mismo instituto católico, Opus Dei, al que pertenecen los colegios del referido Grupo Educativo Fomento, así como el hecho de que dicha circunstancia no fuera advertida en ningún momento por otros miembros del TC, o de que el mismo magistrado, por simple honestidad profesional, no se abstuviera de intervenir en el recurso como, por otras razones, lo hicieron otros dos miembros del Alto Tribunal. Dado que estamos ante un hecho o comportamiento legal —otro supuesto es impensable-, lo menos que puede decirse es que la normativa al respecto permite ser, en determinados casos, juez y parte interesada.
}

11 Sentencia 189/80, de 13 de febrero de 1981, BOE, 24 de febrero de 1981 (suplemento al número 47), 26. El contenido de dicho ideario, su función normativa, y los límites o exigencias que supone, han sido objeto de debates y formulaciones diversas por los tratadistas de modo específico o al abordar los fines del derecho a la educación. Por ejemplo, desde perspectivas ideológicamente y por tanto jurídicamente contrapuestas, en Rafael Báez Serrano, «El ideario educativo de la Constitución española», Iuris Plenum 49 (2016): 111-130, y Benito Aláez Corral, «El ideario educativo constitucional como límite a las libertades educativas», Revista Europea de Derechos Fundamentales 17 (2011): 91-129, y «Artículo 27. El derecho a una educación democrática, libre y plural», en Comentario a la 
relación con la educación y en expresión de Cámara Villar, «nuestra democracia» sea constitucionalmente no neutra, sino «militante».12 Pero tanto en la opinión mayoritaria del TC como en buena parte de los tratadistas, o bien se considera — dígase o no de modo expreso- que se trata de una declaración puramente retórica, sin consecuencias prácticas, dado que admite muy diversas interpretaciones, o bien se entiende que dicha interpretación de la Constitución es la única que cumple dicha finalidad y se adecúa, por tanto, a ese ideario educativo constitucional del que tanto hablan otros tratadistas. ${ }^{13}$

Tampoco ignoran los magistrados que suscriben la sentencia y los tratadistas ideológicamente afines, como es obvio, que los artículos 27.5, 27.7

Constitución española. 40 aniversario 1978-2018. Tomo I (Preámbulo a artículo 96, dirs. Pablo Pérez Tremps y Alejandro Saiz Arnáiz y coord. Carmen Montesinos (Valencia; Tirant lo Blanch, 2018), 601619.

12 Gregorio Cámara Villar, «Sobre el concepto y los fines de la educación en la Constitución española», en X Jornadas de Estudio de la Dirección General del Servicio Jurídico del Estado. Introducción a los derechos fundamentales (Madrid: Ministerio de Justicia, 1988), vol III, 2186.

13 Esta última es, por ejemplo, la posición de Rafael Báez Serrano en «Hacia la consolidación de la constitucionalidad de la educación diferenciada. A propósito de la sentencia del Tribunal Constitucional 31/2018», Revista de Derecho Político 105 (2019): 251-278. Nada extraño en quien asimismo defiende en dicho artículo, como obligación constitucional de los poderes públicos, la promoción «de las libertades educativas a través de la financiación expansiva de los centros docentes»y «la admisión del alumnado» en los centros concertados por su «afinidad» con «el ideario propio» de los mismos (p. 272), o quien, en su tesis doctoral — presentada por el autor en el colegio Altair de Sevilla, del Opus Dei, en su condición de antiguo alumno del mismo (https://www.altair.edu.es/el-antiguo-alumno-rafael-baez-presento-en-altair-su-tesis-sobre-educacion-diferenciada/)_, defendió tanto la constitucionalidad del cheque escolar como la introducción de un modelo dual de educación mixta y diferenciada en la escuela pública española (Rafael Báez Serrano, «Educación diferenciada y conciertos públicos» (Tesis doctoral, Universidad de Sevilla, Departamento de Derecho Constitucional, 2015), 361-371 y 399-407).

Posiciones claramente favorables a la constitucionalidad de la educación separada por sexos e inconstitucionalidad de la exclusión de las ayudas públicas a los centros docentes que implantaren este tipo de enseñanza, fundamentadas en la libertad de elección de centro docente y, sobre todo, el derecho parental a que los hijos reciban una educación acorde con sus convicciones religiosas y morales, pueden verse en María Calvo Charro, «Apoyo de la jurisprudencia española a la educación diferenciada como una opción legítima dentro de la libertad de elección de centro docente de los padres», La Ley 6711 (2007): 1-8, María Isabel de los Mozos Touyá, Educación en libertad y concierto escolar (Madrid: Montecorvo, 1995), y José Luis Martínez López-Muñiz, María Calvo Charro, Alejandro González-Varas Muñiz y María Isabel de los Mozos Touyá, Legitimidad de los colegios de un solo sexo y de su derecho a concierto en condiciones de igualdad (Madrid: Iustel, 2015). Las sentencias del TC 31/2018, de 10 de abril de 2018 y 74/2018, de 5 de julio de 2018 siguen, en general, la línea ideológico-interpretativa marcada por estos tratadistas.

Una buena síntesis expositiva de las distintas posiciones y argumentos sobre el tema, entre los tratadistas y en la jurisprudencia, puede verse en Carlos Vidal Prado, El derecho a la educación en España. Bases constitucionales para el acuerdo y cuestiones controvertidas (Madrid: Marcial Pons, 2017), 75-91. 
y 20.1.c CE establecen el derecho de todos los sectores afectados a participar efectivamente en la programación general de la enseñanza, el del profesorado, padres-madres y alumnado a intervenir en el control y gestión en los centros sostenidos con fondos públicos en los términos que la ley establezca, y la libertad de cátedra, pero siempre y cuando dichos derechos y libertades no pongan en entredicho una concepción restrictiva de la libertad de enseñanza circunscrita a la libertad de creación de centros docentes, de la que, junto con el derecho de los padres a que sus hijos reciban una formación religiosa y moral acorde con sus convicciones, derivan, como acaba de indicarse, el derecho al establecimiento de un ideario por los centros privados y el derecho-libertad a elegir centro docente. Es decir, siempre y cuando los pilares que sostienen su modelo de pluralismo intercentros, declarado así constitucional con exclusión de cualquier otro, sea el que sustente el sistema educativo español. Un modelo en el que el pluralismo político incluido en el artículo 1.1 de la Constitución entre los «valores superiores» del ordenamiento jurídico español — junto a los de la libertad, la justicia y la igualdad-, tenga su reflejo educativo en una libertad de creación de centros docentes que garantice a los padres que pueden elegir para sus hijos un centro acorde con sus convicciones religiosas y morales. Este último, transmutado de derecho-libertad en derecho prestacional, es en definitiva, según dicha interpretación, el derecho fundamental, no el derecho a la educación. Algo todavía más visible en la STC 74/2018, de 5 de julio de 2018, donde, como indican en su voto particular Fernando Valdés Dal-Ré y María Luisa Balaguer Castejón, «la elección de un modelo de educación diferenciada por sexo, [...] pasa a integrar también el derecho de los padres a elegir para sus hijos la formación religiosa y moral que esté de acuerdo con sus propias convicciones, [...] asumiendo un cambio de criterio radical respecto de una jurisprudencia constante y reiterada hace apenas tres meses», en la STC 31/2018, de 10 de abril de 2018, según la cual dicha opción, y el acceso a los conciertos o financiación pública, estaba vinculada no al mencionado derecho (art. 27.3 CE), sino a la libertad de creación de centros con su consiguiente derecho al establecimiento de un ideario de centro (art. 27.6 CE), y a la percepción de ayudas de los poderes públicos por los centros docentes que reúnan los requisitos que la ley establezca (art. 27.9 CE). Es decir, no al servicio de padres y madres, sino del centro docente. ${ }^{14}$

${ }^{14}$ STC 74/2018, de 5 de julio de 2018, 79311-79312. 
El resto de derechos y libertades constitucionales en materia de educación serán todo lo relevantes que sean, así como el fin u objetivo de toda educación expresado en el art. 27.2 CE, pero su alcance no puede limitar o poner en entredicho esa interpretación en cascada de la Constitución que lleva desde la libertad de enseñanza como creación de centros docentes al derecho-libertad de elección de centro, tomando como arco de bóveda interpretativo no ya el derecho a la educación o la susodicha libertad de enseñanza entendida como libertad de creación de centros docentes $-\mathrm{y}$, por tanto, de dirigirlos, establecer un ideario y recibir ayudas públicas-, sino el derecho de los padres a elegir para sus hijos aquella formación religiosa y moral que esté de acuerdo con sus convicciones. Esta es la interpretación, aceptada como doctrina jurisprudencial, que se hace de un artículo de la Constitución, el 27, de naturaleza ambivalente que fue el resultado de un consenso forzado en el que cada parte —el centro-derecha y derecha, por un lado, y el centro izquierda e izquierda, por otro- introdujo parte de su modelo de sistema educativo dejando para más tarde su concreción legal en un sentido u otro. ${ }^{15}$ Solo que, en el contexto de dicha ambivalencia, la magistratura en general, y al más alto nivel, se ha escorado hacia una interpretación que ha sobrevalorado las propuestas de la derecha y el centro-derecha en detrimento de las de la izquierda y el centro-izquierda.

En apoyo de dicha línea interpretativa del texto constitucional, se acude, a partir de la remisión que en el artículo 10.2 CE se hace a la Declaración Universal de Derechos Humanos y los tratados y acuerdos internacionales suscritos por España para interpretar, de conformidad con ellos, los derechos fundamentales y las libertades que la Constitución reconoce, a aquellos convenios declaraciones o tratados en los que, de modo explícito, se recogen la libertad de creación de centros docentes y, bajo unas u otras palabras, el susodicho derecho de los padres a que sus hijos reciban la educación religiosa o moral acorde con sus convicciones. A saber: la Declaración Universal de Derechos Humanos de 10 de diciembre de 1948 (art. 26.2), el Pacto Internacional de Derechos

\footnotetext{
15 Sobre el proceso que condujo a la redacción constitucional del artículo 27 y su ambivalencia, véase Antonio Baylos Grau, «El marco constitucional del derecho a la educación: Debates y proyectos en el período constituyente», en El artículo 27 de la Constitución. Cuaderno de quejas, eds. Manuel de Puelles Benítez y Manuel Menor Currás (Madrid: Morata, 2018), 77-97.
} 
Económicos, Sociales y Culturales de 16 de diciembre de 1966, aprobado por la Asamblea General de las Naciones Unidas el 16 de diciembre de 1966 (art. 13.4), el Pacto Internacional de Derechos Civiles y Políticos, aprobado por la Asamblea General de las Naciones Unidas el 16 de diciembre de 1966 (art. 18), y el Protocolo adicional al Convenio para la Protección de los Derechos Humanos y las Libertades Fundamentales de 4 de noviembre de 1950, aprobado por el Consejo de Europa (art. 2).

Son conocidos la causa y el modo en que se introdujo en el texto constitucional el segundo párrafo del artículo 10 con su remisión interpretativa a los convenios y tratados internacionales suscritos por España. En los debates llevados a cabo en el Congreso de los Diputados, el ponente de la Unión de Centro Democrático en cuestiones educativas, Óscar Alzaga, se había dirigido al líder del Partido Comunista diciéndole que la concepción de la libertad de enseñanza que este último defendía, la de "una escuela única, pero plural», solo cabría reformando el recién acordado artículo 27.16 Pese a ello, pese a que era evidente — como el tiempo ha demostrado-, que el consenso formal -no real- alcanzado tras un conflictivo tira y afloja entre dos concepciones opuestas de lo que se pretendía que fuera el sistema educativo, suponía la renuncia tanto por el Partido Socialista como por el Comunista a aquellos modelos de educación que históricamente habían defendido, por si acaso no hubiera quedado lo suficientemente atado el tema, la Unión de Centro Democrático introdujo en la Comisión Constitucional del Senado - al parecer, previa sugerencia del «cardenal Enrique y Tarancón en público y en privado, en conversaciones directas con el presidente Suárez»—17 el mencionado párrafo segundo del artículo 10 con el objetivo explícito de reforzar la libertad de creación de centros docentes y el derecho de los padres a que sus hijos recibieran una formación religiosa y moral acorde con sus convicciones, así como «el tipo de educación que ha darse a sus hijos», tal y como se expresa en el artículo 26.3 de la Declaración de Derechos Humanos de 1948, y la «libertad de los padres, y en su caso de los tutores legales, de escoger para sus hijos o pupilos escuelas distintas de las creadas por las autoridades públicas,

\footnotetext{
16 Óscar Alzaga Villamil, Comentario sistemático a la Constitución de 1978 (Madrid: Ediciones del Foro, 1978), 255.

17 Soledad Gallego Díaz y Bonifacio de la Cuadra Fernández, "La Constitución», en Memoria de la Transición, coords. Joaquín Prieto, Santos Juliá y Javier Pradera (Madrid: Taurus, 1996), 306.
} 
siempre que aquéllas satisfagan las normas mínimas que el Estado prescriba o apruebe en materia de enseñanza», según reza el artículo 13.3 del Pacto Internacional de Derechos Económicos, Sociales y Culturales de 1966. Lo que sucede es que con el paso del tiempo otros convenios internacionales han venido a poner el acento, entre otras libertades y derechos, en los de las personas menores de 18 años. Libertades y derechos que se contraponen o, al menos, suponen un límite a ese derecho de los padres a moldear a sus hijos a su gusto y manera. Solo que eso sucedería más tarde, en 1989, y era algo que excedía de la capacidad de previsión del futuro de quienes en 1978 promovieron y aprobaron la introducción del segundo párrafo del artículo 10.

\section{LA EDUCACIÓN DIFERENCIADA, SEPARADA O SEGREGADA POR SEXOS. ENCAJE CONSTITUCIONAL}

Una observación previa y no baladí: el título de este capítulo refleja una cuestión terminológico-interpretativa. Al referirse al modelo de educación en el que el alumnado de un sexo es educado en un espacio físico diferente al del otro sexo, los jueces que suscriben la sentencia y defienden no solo su constitucionalidad, sino también el derecho, no limitable por ley, al concierto o ayuda pública de aquellos centros docentes que lo adoptan, hablan de educación «diferenciada». Por el contrario, quienes se oponen al mencionado derecho, o incluso cuestionan su constitucionalidad, hablan de educación «separada» o «segregada». Ambos saben que es a través de las palabras como (re)creamos la realidad.

Recordemos el artículo y los párrafos recurridos. Se trata de los párrafos segundo y tercero del artículo 84.3 de la LOMCE que regula la admisión del alumnado en los centros docentes de titularidad pública o concertados. Su primer párrafo reproduce, sin cambio alguno, la redacción de ese mismo artículo en la LOE de 6 de mayo de 2006: «En ningún caso habrá discriminación por razón de nacimiento, raza, sexo, religión, opinión o cualquier otra condición o circunstancia personal o social». El segundo y el tercer párrafos han sido añadidos al artículo 84.3 por la LOMCE y dicen lo siguiente:

No constituye discriminación la admisión de alumnos y alumnas o la organización de la enseñanza diferenciadas por sexos, siempre que la enseñanza que impartan se desarrolle conforme a 
lo dispuesto en el artículo 2 de la Convención relativa a la lucha contra las discriminaciones en la esfera de la enseñanza, aprobada por la Conferencia General de la UNESCO el 14 de diciembre de 1960.

En ningún caso la elección de la educación diferenciada por sexos podrá implicar para las familias, alumnos y alumnas y centros correspondientes un trato menos favorable, ni una desventaja, a la hora de suscribir conciertos con las Administraciones educativas o en cualquier otro aspecto. A estos efectos, los centros deberán exponer en su proyecto educativo las razones educativas de la elección de dicho sistema, así como las medidas académicas que desarrollan para favorecer la igualdad.

\section{Antecedentes legales y jurisprudenciales de la cuestión debatida (1978-2013)}

Todo arranca del artículo $27.9 \mathrm{CE}$ — Los poderes públicos ayudarán a los centros docentes que reúnan los requisitos que la ley establezca»-, y de su interpretación en relación, sobre todo, con los artículos que establecen la libertad de creación de centros docentes $(27.6 \mathrm{CE})$ y el derecho de los padres a que sus hijos reciban la educación religiosa y moral que esté acorde con sus convicciones religiosas y morales (27.3 CE). Dicho artículo pretendió desarrollarse en principio, por el gobierno de la Unión de Centro Democrático (1979-1982), implantando progresivamente la fórmula del cheque escolar, o sea entregando a las familias una cantidad determinada en función del coste del puesto escolar para que su demanda se dirigiera hacia los centros de su elección. ${ }^{18} \mathrm{El}$ acceso al poder del Partido Socialista en 1982 supuso la configuración legal de un modelo diferente: el de los conciertos escolares sujetos, en cuanto a su concesión, a los requisitos establecidos en las leyes que los regulan y, según doctrina sentada por el TC, a las disponibilidades o limitaciones presupuestarias.

La culminación del proceso de transferencias educativas a las Comunidades Autónomas en los años finales del siglo XX y, entre ellas, de las

\footnotetext{
18 Manuel Otero Novas, Lo que yo viví. Memorias políticas y reflexiones (Madrid: Prensa Ibérica,
} 2015), 253-254. 
decisiones administrativas sobre el acceso, la concesión o no y la renovación de los conciertos, supuso en algunos casos - Andalucía, Castilla-La Mancha, Cataluña, Asturias- su denegación a los centros docentes con educación separada por sexos, por entender que dicho modelo de enseñanza era de naturaleza discriminatoria. ${ }^{19}$ Los recursos planteados contra dichas denegaciones dieron origen a «numerosos pronunciamientos judiciales en los que quedaba reflejado el apoyo al sistema de educación diferenciada». ${ }^{20}$ Un apoyo refrendado por la Sentencia del Tribunal Supremo (TS) de 26 de junio de 2006, confirmando otra anterior de la Audiencia Nacional, de 20 de diciembre de 1999, por entender que la educación diferenciada por sexos no era discriminatoria, y que constituía "parte del derecho de los titulares de una institución de enseñanza a definir el carácter propio, y del derecho de los padres a elegir el centro en que deseaban escolarizar a sus hijos». ${ }^{21}$

La aprobación, sin embargo, de la Ley Orgánica 2/2006, de 3 de mayo, de Educación (LOE), supuso un cambio de criterio en las decisiones judiciales. Cambio que encontraba su apoyo tanto en el artículo 84.3

\footnotetext{
19 Por supuesto, la decisión partía de gobiernos autonómicos de partidos de centro-izquierda. En aquellos ocupados por partidos de derecha o centro-derecha, se implantaba la fórmula del cheque escolar o las exenciones fiscales en la educación infantil, se extendían los conciertos más allá de la educación obligatoria, se financiaba la educación diferenciada por sexos, y se cedía suelo público para construir centros privados, con generosa financiación pública y la concesión automática del concierto - todo ello con un amplio margen de discrecionalidad en cuanto a los titulares de los centros beneficiados - siguiendo el criterio de atender prioritariamente una demanda social promovida desde la misma administración autonómica y/o municipal. Sobre el particular, remito a lo dicho en Antonio Viñao, «El modelo neoconservador de gobernanza escolar: principios, estrategias y consecuencias en España», en La gobernanza escolar democrática, coords. Jordi Collet y Antoni Tort (Madrid: Morata 2016), 41-64.

Esta «diferencia de trato en lo relativo a la financiación pública de la enseñanza privada dentro de un mismo Estado sin más base jurídica que la composición ideológica del gobierno de cada Comunidad Autónoma», ha sido cuestionada por entenderse que en este punto, y en otros como en el de la lengua vehicular de la enseñanza, no se está «respetando la normativa básica común a toda España» ya que, «dependiendo del lugar de residencia, las familias españolas tienen un alcance de sus derechos educativos diferentes» (Juan José Guardia Hernández, «Marco constitucional de la enseñanza privada española mantenida con fondos públicos», 26-27, en https://www.academia. edu/36435006/Marco_constitucional_de_la_ense \%C3\%B1 anza_privada_espa\%C3\%B1ola_sostenida_con_fondos_p\%C3\%BAblicos_recorrido_hist\%C3\%B3rico_y_perspectivas_de_futuro (consultado el 30-07-2019). En este caso, la crítica procede de un tratadista claramente inclinado, desde un punto de vista constitucional, hacia la recentralización, la inclusión en la libertad de enseñanza del derecho a escoger centro docente y, por supuesto, la financiación pública de la educación diferenciada por sexos.
}

20 Centenera Sánchez-Seco, «Educación diferenciada y conciertos educativos», 768.

${ }^{21}$ Alejandro González-Varas Ibáñez, "Régimen jurídico de la educación diferenciada en España», Revista General de Derecho Canónico y Derecho Eclesiástico del Estado 31 (2013), 11. 
de dicha ley al establecer que «en ningún caso habrá discriminación por razón de nacimiento, raza, sexo, religión, opinión o cualquier otra condición o circunstancia personal o social» en el régimen de admisión del alumnado, como, sobre todo, en su Disposición Adicional vigésimo quinta, según la cual,

con el fin de favorecer la igualdad de derechos y oportunidades y fomentar la igualdad efectiva entre hombres y mujeres, los centros que desarrollen el principio de coeducación en todas las etapas educativas, serán objeto de atención preferente y prioritaria en la aplicación de las previsiones recogidas en la presente Ley, sin perjuicio de lo dispuesto en los convenios internacionales suscritos por España.

Así, reconociendo la licitud de la educación diferenciada, el TS, en sentencia de 16 de abril de 2008, admitió la posibilidad de que los centros privados con educación diferenciada por sexos pudiesen ser excluidos de los conciertos, criterio mantenido en sentencias posteriores de dicho tribunal hasta el 2014 si bien con distintos argumentos. En principio, y sin entrar a valorar su índole discriminatoria o no, sosteniendo, como se hacía en la mencionada sentencia de 2008, que el derecho de crear y dirigir centros docentes, no implica, en los centros financiados con fondos públicos, el de elegir al alumnado, tesis reiterada en sentencias posteriores. O bien, que la administración educativa puede exigir o dar prioridad a la educación mixta en dichos centros. A partir de 2012 a los mencionados argumentos se ha unido la posible consideración como discriminatoria de la educación diferenciada por sexos. ${ }^{22}$

La aprobación en 2013 de la LOMCE vino a zanjar la cuestión con los dos párrafos añadidos al artículo 84.3: la educación diferenciada por sexos no constituye discriminación siempre y cuando se cumplan los requisitos establecidos en el artículo 2 de la Convención relativa a las discriminaciones en la esfera de la enseñanza, aprobada por la Conferencia General de la UNESCO en 1960 y, en ningún caso, la elección de la educación diferenciada por sexos podrá implicar un trato menos favorable por parte de las administraciones educativas, o una desventaja, para suscribir conciertos o en relación con cualquier otro aspecto. El

${ }^{22}$ Centenera Sánchez-Seco, «Educación diferenciada y conciertos educativos», 768-769 y 783-784. 
TC, en sentencia de 10 de abril de 2018 vendría a reforzar y ampliar la constitucionalidad de dicho modelo de enseñanza. Y posteriormente, para remachar el clavo, en la sentencia 74/2018, de 5 de julio de 2018, no solo mantendría idéntico criterio sino que, contradiciendo afirmaciones y argumentos de la anterior sentencia, reinterpreta lo dispuesto en la LOE de 2006 - en contra del criterio sostenido repetidamente por el TS desde 2008 a 2014 - por entender que nunca pudo deducirse de ella la posibilidad de que se excluyera de los conciertos a los centros con educación diferenciada por sexos, llegando incluso al despropósito de aplicar retroactivamente dicha interpretación a una resolución denegatoria del concierto de 2009, a la luz de lo dispuesto en el artículo 84.3 de la reforma de la LOE por la LOMCE en 2013.23

\section{La sentencia 31/2018, de 10 de abril de 2018 del TC}

La línea argumental de la sentencia sigue implacablemente, en principio, la interpretación del artículo $27 \mathrm{CE}$ generalizada entre la judicatura y determinados tratadistas: aquella que lleva desde la libertad de enseñanza entendida exclusivamente como libertad de creación de centros docentes a la libertad de elección de centro pasando por el derecho de los padres a que sus hijos reciban la educación religiosa y moral acorde con sus convicciones y el de los centros privados a las ayudas o financiación pública siempre que cumplan los requisitos que la ley establezca. Es decir, a un modelo de sistema educativo con un pluralismo intercentros cuya oferta plural haga posible que los padres puedan elegir aquel centro docente que garantice dicho derecho. Ya sea, se añade, que el modelo de educación diferenciada por sexos se implante para dar respuesta a una «determinada concepción de la vida o cosmovisión con un contenido filosófico, moral o ideológico», o como «un sistema meramente instrumental y de carácter pedagógico, fundado en la idea de optimizar las potencialidades propias de cada uno de los sexos», —una «opción» sobre la que «este Tribunal [...] no puede ofrecer criterio valorativo alguno», pero que no considera «discriminatoria»—, ${ }^{24}$ dicho modelo halla su

\footnotetext{
${ }^{23}$ Sentencia 74/2018, de 5 de julio de 2018. Sobre las contradicciones en que incurre la sentencia, en relación con la 31/2018, de 10 de abril de 2018, véase el voto particular suscrito por Fernando Valdés Dal-Ré y María Luisa Balaguer Callejón, 79307-79313.
}

${ }_{24}$ Sentencia 31/2018, de 10 de abril de 2018, 53564 y 5372. 
apoyo y aval constitucional en el hecho de constituir una manifestación más de la libertad de creación de centros docentes, del derecho de los padres a que sus hijos reciban una educación religiosa y moral acorde con sus convicciones, y de una libre elección de centro docente que se ve así elevada al rango de derecho-libertad constitucional.

Esta línea argumental básica se ve reforzada, además, en la sentencia por «el parámetro exegético» —exigido por el ya aludido artículo 10.2 $\mathrm{CE}$ - «que ofrecen los tratados y acuerdos internacionales ratificados por España». No solo de los tratados y acuerdos antes indicados, de índole general, sino también de aquellos más específicamente relativos a las discriminaciones en el ámbito de la enseñanza y hacia la mujer. Todo ello con el fin de determinar si la educación diferenciada por sexos posee o no un carácter discriminatorio.

Lo dispuesto en los artículos 1 y 2 de la Convención relativa a la lucha contra las discriminaciones en la esfera de la enseñanza, aprobada en la Conferencia general de la UNESCO de 14 de diciembre de 1960, no plantea problema interpretativo alguno al TC. Es cierto que en el artículo 1 se prohibía cualquier «discriminación» educativa, entendiendo por tal «toda distinción, exclusión, limitación o preferencia fundada» entre otras causas o aspectos, en el sexo, y dirigida a «destruir o alterar la igualdad de trato en la esfera de la enseñanza». Sin embargo, el artículo 2 determinaba de modo expreso, y así se recogía en el párrafo segundo del artículo 84.3 de la LOMCE, que no constituía discriminación

la creación o mantenimiento de sistemas o establecimientos de enseñanza separados para los alumnos del sexo masculino y para los del sexo femenino, siempre que esos sistemas o establecimientos ofrezcan facilidades equivalentes de acceso a la enseñanza, dispongan de un personal docente igualmente calificado, así como de locales escolares y de un equipo de igual calidad y permitan seguir los mismos programas de estudio o programas equivalentes. ${ }^{25}$

\footnotetext{
${ }_{25}$ El apartado 33 de la Observación general n 13 relativa al derecho a la educación consagrado en el artículo 13 del Pacto Internacional de Derechos Económicos, Sociales y Culturales de 1966 reitera lo dicho en el artículo 2 de la Convención de 1960.
} 
Más problemático resultaba al TC el llamamiento efectuado a los Estados en la Convención de la ONU sobre eliminación de toda forma de discriminación hacia la mujer, de 18 de diciembre de 1979, ratificada por España el 16 de diciembre de 1983, para estimular «la educación mixta» $\mathrm{y}$ "otros tipos de educación que contribuyan a lograr el objetivo de eliminación de todo concepto estereotipado de los papeles masculino y femenino en todos los niveles y formas de enseñanza». Este requerimiento, que, en efecto, podía cuestionar la línea argumental del TC, fue despachado en la sentencia sin problema alguno: no se trata de una "norma prohibitiva» sino de "fomento», que «no proscribe la existencia de otros modelos educativos». Solo «obliga de manera expresa a estimular el modelo educativo mixto».26 En síntesis, la línea argumental mantenida conduce a la paradójica conclusión de que, a juicio del TC, la financiación pública de la educación diferenciada por sexos no significa que los poderes públicos incumplan la recomendación, efectuada en dicha Convención, de estimular la educación mixta.

Declarada constitucional y no discriminatoria la educación diferenciada por sexos, los dos pasos siguientes eran ineludibles. Desde luego, los centros docentes que optaren por dicho modelo podían acceder sin problema alguno, según el TC, al sistema de conciertos o ayudas públicas, en los términos expresados en el párrafo tercero del artículo 84.3 de la LOMCE. Pero el TC va más allá al establecer como doctrina jurisprudencial no ya el derecho de los centros que optan por la educación diferenciada por sexos a suscribir conciertos, sino la prohibición al poder legislativo de excluir en el futuro del sistema de conciertos a dichos establecimientos docentes, tal y como se interpretaba a partir del artículo 84.3 y de la Disposición adicional vigésimo quinta de la LOE en 2006. En otras palabras, la existencia de los conciertos educativos está avalada constitucionalmente por el artículo 27.9 CE al establecer que «los poderes públicos ayudarán a los centros docentes que reúnan los requisitos que la ley establezca», y, en cuanto a la «enseñanza básica», por su doble carácter obligatorio y gratuito (artículo 27.4 CE). En último término, dichos conciertos, sigue afirmando el TC, «están enmarcados en el ámbito prestacional del más genérico derecho a la educación» y son una exigencia tanto del «derecho a la creación de centros docentes» como

${ }^{26}$ Sentencia 31/2018, de 10 de abril de 2018, 53567. 
del «derecho de los padres a elegir centro docente», al menos en el ámbito de la educación obligatoria. ${ }^{27} \mathrm{Y}$ aunque sea cierto, que el artículo 27.9 CE «no encierra [...] un derecho subjetivo a una prestación pública [...], ello no significa, sin embargo, que el legislador sea enteramente libre para configurar el régimen prestacional» que ampara, sino que «la Ley que reclama el artículo 27.9 no podrá, en particular, contrariar los derechos y libertades educativas presentes en el mismo artículo y deberá, asimismo, configurar el régimen de ayudas en el respeto al principio de igualdad». ${ }^{28}$ Es decir, aunque no existe un derecho subjetivo al concierto educativo, puesto que ello depende, entre otros aspectos, de las disponibilidades presupuestarias, en el futuro habrá que considerar inconstitucional toda normativa sobre los conciertos que exija la coeducación para acceder a los mismos, ya que ello se opondría a los artículos 27.3, 27.4 y 27.6 CE, así como al derecho de los padres a elegir centro docente que de dichos artículos se deriva.

La conclusión del TC, a partir de dicha línea argumental, es clara y terminante:

No existe dato alguno que permita llegar a la conclusión de que dicho sistema [el de la educación diferenciada], en cuanto tal, no sirve a los fines exigidos constitucionalmente, y en particular, a la conclusión de que no está inspirado en principios democráticos de convivencia o en los derechos y libertades fundamentales, o de que no cumplan los objetivos marcados por las normas generales.

Por lo tanto, dado que no existe ningún elemento que conduzca a imputar a la educación diferenciada una incapacidad estructural para el logro de los objetivos educativos marcados constitucionalmente, lo determinante será el análisis de cada centro en particular.

En consecuencia, y dado que las ayudas públicas previstas en el artículo 27-9 CE han de ser configuradas «en el respeto al principio de igualdad» (STC 86/1985, FJ 3), sin que quepa justificar un diferente tratamiento entre ambos modelos pedagógicos, en orden a su percepción, la conclusión a la que ha de llegarse es la

\footnotetext{
27 Sentencia 31/2018, de 10 de abril de 2018, 53573.

${ }_{28}$ Sentencia 31/2018, de 10 de abril de 2018, 53574 y 53575.
} 
de que los centros de educación diferenciada podrán acceder al sistema de financiación pública en condiciones de igualdad con el resto de los centros educativos; dicho acceso vendrá condicionado por el cumplimiento de los criterios o requisitos que se establezcan en la legislación ordinaria, pero sin que el carácter del centro como centro de educación diferenciada pueda alzarse en obstáculo para dicho acceso. ${ }^{29}$

\section{Los votos particulares (I): el TC es intérprete supremo de la Constitución, no legislador}

Un voto particular, el de la Vicepresidenta del TC, Encarnación Roca Trías, comparte con la sentencia que la «educación diferenciada no puede considerarse un supuesto de discriminación por razón de sexo" proscrito por el artículo $14 \mathrm{CE},{ }^{30}$ pero discrepa de la misma en un punto que será también objeto de disentimiento en el resto de los votos particulares: el de su extralimitación, al ir más allá del recurso y declarar inconstitucional cualquier norma futura que circunscriba la financiación pública a los centros privados mixtos, excluyendo a los de educación diferenciada por sexos. Como terminantemente afirma Encarnación Roca, el TC «es intérprete supremo de la Constitución, no legislador» y «el derecho a la subvención no nace para los centros de la Constitución, sino de la ley». ${ }^{31}$

En efecto, como ha observado un reconocido tratadista, en esta sentencia el TC ha introducido «una novedad de primera magnitud»: «cualquier colegio que opte por un ideario educativo no inconstitucional tiene derecho a no ser tratado de manera diferente por razón del modelo elegido en ejercicio de la libertad de enseñanza. Basta con querer implantar un modelo [educativo] que no sea inconstitucional para tener derecho a obtener [...] financiación pública». La sentencia convierte, de este modo, «un derecho subjetivo de autonomía», el derecho a la libertad de enseñanza, en un derecho "prestacional». ${ }^{32}$

\footnotetext{
${ }_{29}$ Sentencia 31/2018, de 10 de abril de 2018, 53576-53577. Cursiva propia.

${ }^{30}$ Sentencia 31/2018, de 10 de abril de 2018, 53603.

${ }^{31}$ Sentencia 31/2018, de 10 de abril de 2018, 53603 y 53604.

32 Luis Arroyo Jiménez, «Un año de doctrina constitucional», 11. En https://www.academia. edu/38322895/Un_a\%C3\%B1o_de_doctrina_constitucional (consultado el 30-01- 2019). Texto escrito
} 
Bajo la cuestión planteada subyace, en el fondo, otra de más calado. La firmante del voto particular expresa su creencia de que «una decisión del legislador que, hipotéticamente, limitase la financiación pública a los centros privados mixtos no vulneraría la libertad de educación [sic] ni la libertad de creación de centros docentes (arts. 27.1 y 6 CE) de los titulares de los centros privados de educación diferenciada», como tampoco lo hace el artículo 84.3 de la LOMCE cuando establece que la elección de esta última no puede implicar un trato menos favorable o una desventaja a la hora de suscribir los conciertos o en cualquier otro aspecto. Ambas opciones, la que restringe los conciertos a la educación privada mixta o la que los extiende, en pie de igualdad, a la diferenciada por sexos, concluye, constituyen legítimas opciones dentro del marco constitucional. ${ }^{33}$

de la ponencia impartida el día 25 de septiembre de 2018 en las XXIV Jornadas de la Asociación de Letrados del Tribunal Constitucional.

33 Sentencia 31/2018, de 10 de abril de 2018, 53604-53605. Sobre el tema ha mostrado sus reservas Aláez Corral para quien la constitucional decisión del legislador en favor de una de las dos opciones «no debería impedir [...] que la menor predisposición estructural hacia la coeducación que algunos estudios pedagógicos imputan a la educación diferenciada —en comparación con la educación mixta - y de la que se hace eco el artículo 10.c) de la Convención de las Naciones Unidas sobre la eliminación de todas las formas de discriminación contra la mujer de 1979 apelando al estímulo de la última como uno de los medios para lograr los estereotipos de género y la igualdad entre hombres y mujeres, pueda ser tenida en cuenta por los poderes públicos al regular los requisitos para que los centros privados reciban ayudas públicas [...]. Debería ser el Parlamento, en tanto que expresión de la soberanía de las generaciones vivas, quien determine, en desarrollo de los artículos 9.2 y 27.9 CE, cuáles son las medidas razonablemente adecuadas para educar conforme a una igualdad real y efectiva de hombres y mujeres, y si debe excluirse de la ayuda económica a la educación diferenciada, lo que en la actualidad (desde la reforma de la LOE de 2013) ya no sucede. Sin embargo, la más reciente jurisprudencia constitucional (STC 31/2018, de 10 de abril, FJ 4 y STC $74 / 2018$, de 5 de julio, $F J 4^{\circ} \mathrm{c}$ ) ha cerrado la puerta a ese margen de valoración legislativa, equiparando binariamente la no oposición de la educación diferenciada a los derechos y libertades fundamentales ni al ideario educativo constitucional, con la equivalencia funcional de la educación diferenciada y de la educación mixta a la hora de dar cumplimiento positivo a ese ideario, lo que crea [...] una ficción igualitaria de ambos modelos pedagógicos que tampoco está científicamente acreditada y no corresponde al Tribunal Constitucional determinar» (Aláez Corral, «Artículo 27», 610-611). Sobre la posición al respecto de este autor con anterioridad a la reforma de la LOE por la LOMCE, véase «El ideario educativo constitucional como fundamento de la exclusión de la educación diferenciada por razón de sexo de la financiación pública», Revista Española de Derecho Constitucional 86 (2009): 31-64.

Con anterioridad a la sentencia sobre la LOMCE, el criterio de Cotino Hueso ( «El derecho a la educación», 433) abre todavía más las opciones constitucionalmente válidas del legislador: «A nuestro juicio, en el marco constitucional cabe tanto optar por la enseñanza separada en los centros públicos, cuanto, en el extremo contrario, sería posible imponer la coeducación conjunta incluso en la enseñanza privada no subvencionada. Se trata de una decisión legítima que debe adoptar y asumir el legislador». 
La cuestión de fondo no es, sin embargo, tan simple. Como indica Arroyo Jiménez, la fundamentación de la sentencia y con ella, añado, la del voto particular de la vicepresidenta del TC, ofrece «dos debilidades fundamentales». Por un lado, «descarta apresuradamente que la segregación [por sexos] sea discriminatoria». Por otro, "parece asumir que los límites que, en su caso, podría plantear el artículo 27.2 CE [«La educación tendrá por objeto el pleno desarrollo de la personalidad humana en el respeto a los principios democráticos de convivencia y a los derechos y libertades fundamentales»] a la autonomía de quien ejerce la libre creación de centros son los derivados del derecho a la igualdad». Es decir, del artículo $14 \mathrm{CE}$ que establece el principio de igualdad ante la ley y la consiguiente no discriminación por razón del sexo, entre otros aspectos de índole personal o social. Sin embargo, continua Arroyo Jiménez, el mencionado artículo 27.2 CE «opera como un interfaz que obliga a interpretar sistemáticamente el artículo $27 \mathrm{CE}$ en relación» no solo con el artículo $14 \mathrm{CE}$, sino también con otros principios constitucionales, en especial con los establecidos en el artículo 1.1 CE, según el cual «España se constituye en un Estado social y democrático de Derecho, que propugna como valores superiores de su ordenamiento jurídico la libertad, la justicia, la igualdad y el pluralismo». En síntesis, «esta perspectiva, la de las implicaciones que los principios de democracia y pluralismo» (art. 1.1. CE) tienen respecto de la configuración del sistema educativo (art. 27.2 CE) «permanece completamente inédita en la sentencia comentada». ${ }^{34} \mathrm{O}$ sea, es ignorada o, si se prefiere, permanece en un espacio ciego, tanto para los jueces que suscriben la sentencia como en el voto particular de la vicepresidenta del TC. No será así, como se verá de inmediato, en el resto de los votos particulares.

\section{Los votos particulares (II): naturaleza discriminatoria e inconstitucional de la educación separada por sexos}

Primera cuestión clave: la educación separada por sexos en los centros privados concertados ¿vulnera o no la prohibición constitucional de discriminación por razón de sexo (art. 14 CE)? Para la sentencia, la opinión mayoritaria del TC que sienta doctrina jurisprudencial, y para su vicepresidenta, dicho modelo educativo no es discriminatorio per se.

\footnotetext{
34 Arroyo Jiménez, «Un año de doctrina constitucional», 10.
} 
Puede serlo - habría que analizarlo en cada caso-, pero no si se cumplen las condiciones establecidas en el artículo 84.3 de la LOMCE. Sin embargo, la sentencia, como indica Juan Antonio Xiol en su voto particular, va más allá en sus razonamientos y valoraciones de la constitucionalidad o no de dicho artículo, hasta el punto de no «alejar cualquier tipo de duda respecto de la imposibilidad de que la segregación sexual sea implantada en los centros docentes públicos». ${ }^{35}$ En efecto, si la segregación sexual binaria es constitucional, se abre la puerta, si el gobierno de turno considera que es un mejor modelo pedagógico - o simplemente por razones ideológicas - a que también pueda ser implantada en la red escolar pública o, al menos, a que se deje tal decisión en manos de los consejos escolares de cada centro docente. De ahí que tres de los cuatro votos particulares emitidos - uno de ellos firmado por dos jueces- centren su análisis en la naturaleza constitucional o inconstitucional de lo que denominan separación o segregación por sexos en los centros financiados con fondos públicos —aunque, como se verá, sus razonamientos y valoraciones puedan extenderse también a los centros privados no concertados.

En primer lugar, «toda diferenciación por razón de sexo debe superar un escrutinio particularmente riguroso»; se trata de una categoría «intrínsecamente sospechosa» de producir un tipo de discriminación «de los más invisibilizados, persistentes, extendidos y trivializados». De ahí que las «causas» que subyacen en dicha diferenciación deban ser objeto de un «cuidadoso análisis», junto con el de sus «antecedentes históricos», algo que no lleva a cabo la sentencia o lo hace de modo insuficiente. ${ }^{36}$

El análisis de los «antecedentes históricos» lleva, así, a Fernando Valdés y Cándido Conde-Pumpido a mantener que la «llamada educación diferenciada más parece un eufemismo de cariz pseudomoderno, [...] apenas distante de la idea que sostuvo la segregación tradicional, de manifiesto y grueso trato discriminatorio», perpetuando así el «estigma de

\footnotetext{
35 Sentencia 31/2018, de 10 de abril de 2018, 5363.

36 Sentencia 31/2018, de 10 de abril de 2018, 53608 (voto particular de Fernando Valdés Dal-Ré y Cándido Conde-Pumpido Tourón), 53614 y 53615 (voto particular de Juan Antonio Xíol Ríus) y 53631 (voto particular de María Luisa Balaguer Callejón).
} 
este legado con el "nuevo ropaje" de una opción pedagógica».37 Para Juan Antonio Xiol, la opción por este tipo de educación responde a «estereotipos sexistas ancestrales que arrastramos individualmente como tributo de nuestra educación en los valores de la sociedad que nos ha tocado vivir». Item más, "concurren ciertas circunstancias en el caso español» que «permiten mantener las dudas de que ese argumento tópico [el de las diferentes aptitudes entre los hombres y las mujeres], bajo la apariencia de una neutralidad metodológica, encubre prejuicios ideológicos», en especial si tiene en cuenta que

(i) muchos de los colegios privados, ahora concertados, que tiene[n] implantada la segregación sexual siguen este modelo desde los años $60 \mathrm{y}$, por tanto, están fundados en un contexto normativo en que [...] la segregación sexual se fundamentaba en la necesidad de aportar una educación diferenciada por sexos para adaptar los programas educativos al cumplimiento de roles sociales sexistas, y (ii) un número de estos centros están vinculados con idearios que sostienen posiciones particularistas sobre distribución de roles sociales entre los sexos. ${ }^{38}$

El juicio de María Luisa Balaguer no es menos duro y terminante: «la Sentencia da un paso atrás en la historia» y «retrocede en el tiempo [...] a un momento anterior al año 1970, en que se implantó en el Estado la educación mixta preconstitucional». ${ }^{39}$ Corresponde y refleja los estereotipos predominantes en otra época y régimen político sin que, a juicio de Juan Antonio Xiol, se perciba

que la opinión mayoritaria [en el seno del TC] haya realizado ese esfuerzo de racionalización para situar el análisis de la segregación sexual escolar a la altura de los tiempos y de la alta dignidad que nos debemos como sociedad que ha tomado conciencia de que debe ser superado cualquier paradigma sexista. ${ }^{40}$

\footnotetext{
37 Sentencia 31/2018, de 10 de abril de 2018, 53609 y 53610.

38 Sentencia 31/2018, de 10 de abril de 2018, 53617 y 53623.

${ }_{39}$ Sentencia 31/2018, de 10 de abril de 2018, 53629 y 53630.

40 Sentencia 31/2018, de 10 de abril de 2018, 53617.
} 
Por supuesto, la lectura que se efectúa en los votos particulares de los acuerdos y tratados internacionales relativos al caso difiere de la llevada a cabo en la sentencia. La requisitoria a los Estados miembros de la ONU para que estimulen la «educación mixta» como un instrumento para la «eliminación de todo concepto estereotipado de los papeles masculino y femenino en todos los niveles y en todas las formas de la enseñanza», efectuada en el artículo 10.c de la Convención de 1979 sobre la eliminación de todas las discriminaciones contra la mujer, es entendida tanto en el voto particular de Juan Antonio Xiol como en el de María Luis Balaguer, como algo más, mucho más que una mera recomendación, en especial tratándose de centros docentes financiados con fondos públicos. Constituye, a su juicio, un elemento interpretativo más del artículo $27 \mathrm{CE}$, y del caso debatido, en favor de la inconstitucionalidad de la educación separada por sexos. ${ }^{41}$

Pero es en el voto particular de esta última magistrada donde más insistencia y amplitud se hace del recurso a los acuerdos y tratados internacionales para sustentar su juicio negativo sobre la constitucionalidad de la educación diferenciada. De forma expresa, además, discrepa de la interpretación, a su juicio "forzada» - yo añadiría parcial, incompleta y sesgada- que la sentencia efectúa del artículo 10.2 CE. Una interpretación regresiva, añade, del «alcance del derecho a la educación», que lo contextualiza «en un tiempo histórico del que han pasado ya más de 40 años». ${ }^{42}$

En efecto, como indica esta magistrada, la Convención relativa a la lucha contra las discriminaciones en la esfera de la enseñanza, aprobada por la Conferencia General de la UNESCO el 14 de diciembre de 1960, a cuyo artículo 2 se refiere el artículo 84.3 de la LOMCE, en el que se apoya la sentencia del TC como criterio sustentador o aval de que la educación diferenciada por sexos no constituye discriminación, fue ratificada en 1969 «cuando no existía en nuestro país la educación mixta a la que se abre el modelo español con la Ley General de Educación de 1970».43 Y desde entonces se han aprobado diversos acuerdos o tratados

\footnotetext{
${ }^{41}$ Sentencia 31/2018, de 10 de abril de 2018, 53616, 53618 y 53632.

42 Sentencia 31/2018, de 10 de abril de 2018, 53631.

43 Sentencia 31/2018, de 10 de abril de 2018, 53631.
} 
internacionales que la sentencia considera, en unos casos, irrelevantes -el llamamiento para estimular la educación mixta efectuado en la mencionada Convención de 1979_-, y en otros, aquejada de ceguera, los obvia por considerar implícitamente que no guardan relación alguna con el asunto debatido.

La sentencia, continua esta magistrada, ignora, o estima irrelevante y sin relación con el caso, que el artículo 29 de la Convención de las Naciones Unidas de 20 de noviembre de 1989 sobre los derechos del niño, establezca, como límite a la libertad de creación de centros docentes, el cumplimiento, entre otros objetivos, del de

preparar al niño para asumir una vida responsable en una sociedad libre, con espíritu de comprensión, paz, tolerancia, igualdad de sexos y amistad entre todos los pueblos, grupos étnicos, nacionales y religiosos y personas de origen indígena.

De igual modo, la sentencia desconoce o considera que no tiene nada que ver con el tema el hecho de que el artículo 14 del Convenio del Consejo de Europa sobre prevención y lucha contra la violencia contra la mujer y la violencia doméstica, de 11 de mayo de 2011, establezca que los gobiernos incluirán

en los programas de estudios oficiales y a todos los niveles de enseñanza material didáctico sobre temas como la igualdad entre mujeres y hombres, los papeles no estereotipados de los géneros, el respeto mutuo, la solución no violenta de conflictos en las relaciones interpersonales, la violencia contra la mujer por razones de género y el derecho a la integridad personal, adaptado a la fase de desarrollo de los alumnos. ${ }^{44}$

En el voto particular de Juan Antonio Xiol se introduce, además, una cuestión que merece una reflexión adicional. Una cuestión anunciada ya cuando, al comienzo de dicho voto, sostiene que «la segregación sexual binaria vulnera la prohibición constitucional de la discriminación por razón de sexo e identidad sexual». ${ }^{45}$ El término "binaria» y la expresión «identidad sexual» sitúan el debate en el espacio más

\footnotetext{
${ }^{44}$ Sentencia 31/2018, de 10 de abril de 2018, 53631 y 53632.

45 Sentencia 31/2018, de 10 de abril de 2018, 53613.
} 
amplio de la diversidad de orientaciones sexuales y del sector de población conocido con las siglas LGTBI. En efecto, «la segregación sexual binaria», dirá más adelante, «excluye con carácter absoluto a las personas intersexuales del ámbito educativo». La sentencia se basa en un «prejuicio» más, el de

que solo existen dos únicos sexos y que todo individuo ha de tener encaje en uno de ellos. Cualquier normativa basada en el prejuicio de la dualidad sexual provoca un inmediato efecto de exclusión total de aquellas personas, como las intersexuales, que no pueden ser identificadas con ninguno de estos dos sexos, provocando con ello una nueva forma de discriminación, en este caso no por segregación, sino por exclusión. ${ }^{46}$

El mismo autor del voto particular indica que planteó «en las deliberaciones sin éxito [...] que se abordara esta cuestión y se le diera respuesta en términos constitucionales». Su valoración, en este punto, de la sentencia no puede ser más negativa:

No puedo imaginar la violencia institucional y el sentido de desolación y abandono que para estas personas implica ser radicalmente negados por el ordenamiento jurídico y que se les imponga una identidad sexual que ni tienen ni sienten necesariamente como propia a modo de ficción legal para que puedan ser integrados socialmente. Esta consideración y mi profundo convencimiento de la necesidad de respetar la diversidad como fundamento de una sociedad democrática es otro de los elementos que me lleva a afirmar ya no solo el carácter intrínsecamente sospechoso de discriminación por razón de sexo de la segregación sexual binaria sino, directamente, su carácter discriminatorio por razón de identidad sexual respecto de los intersexuales por representar su forma extrema y por ello nunca justificable: su negación y exclusión radical. ${ }^{47}$

\footnotetext{
46 Sentencia 31/2018, de 10 de abril de 2018, 53619.

47 Sentencia 31/2018, de 10 de abril de 2018, 53619 y 53620. El argumento es asimismo utilizado en el voto particular de Fernando Valdés y Cándido Conde-Cumpido: la educación diferenciada por sexos, sostienen, dificulta «la lucha contra la discriminación basada en la orientación sexual y la identidad de género, en línea opuesta con la necesidad de avanzar en la protección de los derechos de las personas LGTBI» (Sentencia 31/2018, de 10 de abril de 2018, 53607).
} 
Tras dicha valoración se esconde, además, un «fracaso» personal, nos dice al final de su voto Juan Antonio Xiol, «en la capacidad de persuasión para conformar una opinión mayoritaria». Así finaliza du voto particular:

El fracaso de quienes pensamos así ha consistido en que ni siquiera hemos sido capaces de convencer a la mayoría en lo que considero [...] una regresión en la lucha por una sociedad libre de la lacra del sexismo. Lamento que haya sido así, pero soy consciente de que solo formo parte de una inmensa minoría en la defensa de la erradicación de cualquier tipo de discriminación sexual. Me es mucho más difícil de sobrellevar la carga de que, además, esta opinión mayoritaria supone un lastre en el progreso hacia una sociedad más igualitaria sexualmente y libre de cualquier prejuicio de binarismo sexual. Algún día, espero no muy lejano, sueño tener la posibilidad de celebrar que la sociedad se ha elevado y trascendido a cualquier tipo de segregación sexual. Mientras tanto [...] solo me resta decir: cuando están en juego los derechos fundamentales de los ciudadanos, niego categóricamente a los legisladores o a los jueces la posibilidad de fijarse en su sexo o identidad sexual. ${ }^{48}$

\section{Los votos particulares (III): existe un ideario educativo constitucional según el cual el servicio público de la educación constituye un espacio de socialización en valores democráticos}

Los tres votos particulares emitidos por Fernando Valdés, Cándido Conde-Pumpido, Juan Antonio Xiol y María Luisa Balaguer se fundamentan en último término, de modo más o menos detallado, en un hecho no tenido en cuenta en la sentencia o del que no se extraen las consecuencias pertinentes: existe un ideario o modelo educativo constitucional contenido, de modo particular, en el artículo 27.2 CE [«La educación tendrá por objeto el pleno desarrollo de la personalidad humana en el respeto a los principios democráticos de convivencia y a los derechos y libertades fundamentales»] y, desde una perspectiva general —aplicable también a otros ámbitos de la vida social y política一, en los artículos 1.1 CE [«España se constituye en un Estado social y democrático de Derecho, que propugna como valores superiores de su ordenamiento jurídico la libertad, la justicia, la igualdad y el

${ }^{48}$ Sentencia 31/2018, de 10 de abril de 2018, 53627-53628. 
pluralismo político»], 9.2 CE [«Corresponde a los poderes públicos promover las condiciones para que la libertad y la igualdad del individuo y de los grupos en que se integra sean reales y efectivas»] y $14 \mathrm{CE}$ [«Los españoles son iguales ante la ley, sin que pueda prevalecer discriminación alguna por razón de nacimiento, raza, sexo, religión, opinión o cualquier otra condición o circunstancia personal o social»]. Y, como advierte Arroyo Jiménez en su análisis de la sentencia sobre la LOMCE, «esta perspectiva», la de que este ideario, con su fundamentación axiológica, suponga un límite a la libertad de creación de centros y constituya la base para la configuración de un sistema educativo que no solo prohíba o impida la discriminación, sino que «proporcione a los niños y niñas una educación funcional al desarrollo de ciudadanos libres e iguales en el marco de una sociedad democrática que es, precisamente por serlo, una sociedad plural y heterogénea, [...] permanece totalmente inédita en la sentencia comentada». ${ }^{49}$ Una vez más, ceguera ante hechos evidentes y normativas vigentes. Ni siquiera se entran a considerar y debatir; se ningunean. No existen.

Así, frente a la inanidad con la que buena parte de la judicatura y tratadistas consideran el artículo 27.2 CE —una mera declaración ideológica formal, u objetivo ideal sin consecuencias jurídicas o prácticas-, los magistrados Fernando Valdés y Cándido Conde-Pumpido sostienen que

el artículo 27.2 no ampara el adoctrinamiento ideológico, por contrario a los valores superiores de la libertad y el pluralismo. Pero tampoco es neutral, en cuanto impulsa decididamente la difusión de valores constitucionales: juridifica así la médula de la educación democrática. ${ }^{50}$

En apoyo, como antecedente del caso, los firmantes de los tres votos particulares que comentamos recurren a lo mantenido por el TC en la sentencia 133/2010, de 2 de diciembre. Como indica María Luisa Balaguer, en la sentencia sobre la LOMCE el TC pierde la oportunidad de desarrollar «una noción de modelo educativo constitucional sobre la base de lo esbozado en la STC 133/2010» donde se descarta el homeschooling como modelo educativo básico en nuestro sistema constitucional, y se produce la aproximación a una definición de dicho modelo, al afirmar que

\footnotetext{
49 Arroyo Jiménez, «Un año de doctrina constitucional», 10.

${ }^{50}$ Sentencia 31/2018, de 10 de abril de 2018, 53607.
} 
la educación a la que todos tienen derecho y cuya garantía corresponde a los poderes públicos como tarea propia, no se contrae, por tanto, a un proceso de mera transmisión de conocimientos [...], sino que aspira a posibilitar el libre desarrollo de la personalidad y las capacidades de los alumnos [...] y comprende la formación de ciudadanos responsables en el marco de una sociedad plural $[. .$.$] en condiciones de igualdad y tolerancia, y con pleno$ respeto a los derechos y libertades fundamentales del resto de sus miembros. ${ }^{51}$

Un modelo educativo constitucional - como asimismo se dice en la sentencia 133/2010 - en el que esa «formación de ciudadanos respetuosos con los principios democráticos de convivencia y con los derechos y libertades fundamentales», que se establece como objetivo de la educación en el artículo 27.2 CE,

se ve satisfecha más eficazmente mediante un modelo de enseñanza básica en el que el contacto con la sociedad plural y con los diversos y heterogéneos elementos que la integran, lejos de tener lugar de manera puramente ocasional y fragmentaria, forma parte de la experiencia cotidiana que facilita la escolarización. ${ }^{52}$

«En otras palabras», añade Arroyo Jiménez, «la razón por la cual el deber de escolarización no fue entonces declarado inconstitucional es que la escuela permite el contacto cotidiano entre personas diferentes y eso es especialmente valioso desde la perspectiva del artículo $27 \mathrm{CE} . »^{53}$ Esta concepción de la escuela, sostienen Fernando Valdés y Cándido Conde-Cumpido, como «espacio por excelencia de socialización y convivencia en la igualdad desde la infancia más cercana», ${ }^{54}$ implica, en relación con el asunto objeto del recurso de inconstitucionalidad, que «determinadas habilidades sociales, valores, capacidades y dimensiones del desarrollo de la personalidad [...] no pueden "aprenderse" y "entrenarse" más que si el segundo espacio de socialización que es la escuela, reproduce esos mismos espacios mixtos, como premisa de una coeducación

\footnotetext{
51 Sentencia 31/2018, de 10 de abril de 2018, 53633.

52 Arroyo Jiménez, «Un año de doctrina constitucional», 10.

53 Arroyo Jiménez, «Un año de doctrina constitucional», 10.

54 Sentencia 31/2018, de 10 de abril de 2018, 53607.
} 
efectiva». En conclusión, la educación diferenciada posee «una incapacidad estructural, u ontológica, para el logro de los objetivos marcados constitucionalmente». ${ }^{55}$ Solo la «educación mixta proporciona», a juicio de ambos magistrados, "los cimientos de convivencia entre iguales que posibilita el cumplimiento del ideario educativo de la Constitución». Su tesis interpretativa es concluyente: «En nuestro sistema constitucional, la desigualdad (la segregación) se encuentra vedada en las escuelas, tanto públicas como privadas, por imperativo de los arts. 1, 9.2, 14 y 27.2 CE.»56

\section{PALABRAS FINALES: IDEARIO EDUCATIVO CONSTITUCIONAL, DERECHOS Y LIBERTADES DE LOS MENORES Y PLURALISMO EDUCATIVO}

Solo unas palabras - a modo de cierre de esta primera parte del ensayo y avance de la segunda- sobre las implicaciones o exigencias de ese ideario o modelo educativo constitucional ignorado en la sentencia sobre la LOMCE, y planteado en algunos de sus votos particulares. Todo ello en relación con la Convención sobre los derechos del niño de 20 de noviembre de 1989, aprobada por la Asamblea General de las Naciones Unidas y ratificada por España el 30 de noviembre de 1990 — sobre cuya «ceguera» versará la segunda parte del ensayo-y el tipo de pluralismo educativo constitucional vigente en España.

¿Es posible hallar alguna referencia a dicha Convención en la sentencia del TC sobre la LOMCE o en algunos de los votos particulares? Desde luego, para los miembros del TC que mayoritariamente suscriben la sentencia, la Convención de 1989 no existe y, caso de existir, ni se menciona por entender que no afecta a los temas tratados en ella. Por lo que respecta a los votos particulares, encontramos dos alusiones. La de los magistrados Fernando Valdés y Cándido Conde-Pumpido efectuada no directamente a la Convención, sino a un desarrollo de ella: la Observación número 12, de 12 de junio de 2009, del Comité de Naciones Unidas de Derechos del Niño, que alude de modo específico al «derecho del niño a ser escuchado en las cuestiones relativas al rendimiento escolar». ${ }^{77} \mathrm{Y}$ la

\footnotetext{
55 Sentencia 31/2018, de 10 de abril de 2018, 53633. Voto particular de María Luisa Balaguer.

56 Sentencia 31/2018, de 10 de abril de 2018, 53608 y 53610.

57 Sentencia 31/2018, de 10 de abril de 2018, 53612 .
} 
de María Luisa Balaguer, cuando recuerda, para fundamentar su oposición constitucional a la educación diferenciada por sexos, que el artículo 29.2 de la Convención de 1989 reconoce la libertad de creación y dirección de centros docentes siempre y cuando se respeten los fines de la educación establecidos en el 29.1 y, entre ellos, en concreto, el de que la educación impartida esté dirigida a preparar al alumnado para que asuma «una vida responsable« basada, entre otros aspectos, en la «igualdad de sexos». ${ }^{58}$ Bien poco para una Convención vigente en el ordenamiento constitucional, desde su ratificación en 1990, en virtud de los artículos 10.2 y 39.4 CE. Dejo solo apuntada esta cuestión que, como quedó dicho, constituirá el tema central de la segunda parte del ensayo, y adelanto, a modo de esbozo, que divergencias interpretativas básicas existen en relación con la noción de pluralismo en el ámbito de la educación.

La interpretación hasta ahora vigente sobre el modelo educativo constitucional desde la perspectiva del pluralismo exigido por el artículo $1 \mathrm{CE}$ es la del «pluralismo intercentros»: la libertad de creación de centros docentes y el derecho de los padres a que sus hijos reciban una educación acorde con sus convicciones religiosas y morales exigen que el pluralismo social e ideológico existente se refleje en una oferta educativa plural, financiada con fondos públicos, de tal modo que las familias puedan elegir el centro docente, bien entendido que si se trata de un centro de titularidad pública debe regir el principio de neutralidad, no aplicable a los centros privados aun en el supuesto de que reciban fondos públicos. Frente a esta concepción del pluralismo educativo se han alzado y se alzan quienes defienden un "pluralismo intracentros» en el que todos los establecimientos docentes sostenidos o que reciben fondos públicos reflejen en su ideario o proyecto de centro, y en su práctica diaria, el pluralismo social existente.

El ideario educativo constitucional, tal y como ha sido esbozado en los votos particulares de la sentencia sobre la LOMCE y por determinados tratadistas va más allá. No solo obliga al TC a revisar su concepto de neutralidad —un concepto pasivo, aséptico, propio de quien no toma parte y se abstiene- sustituyéndolo por el de «pluralismo educativo»: un concepto activo, axiológico, que obliga a mostrar las distintas opciones existentes en relación con un tema proporcionando una información

\footnotetext{
${ }^{58}$ Sentencia 31/2018, de 10 de abril de 2018, 53632.
} 
plural. Es decir, a tener en cuenta en la enseñanza de cualquier materia o cuestión por el docente, o en el material didáctico de que se trate, la diversidad de posiciones existentes, más o menos mayoritarias, más o menos consistentes, y el necesario recurso a la duda o el cuestionamiento en los temas tratados. Por supuesto, ello plantea el problema de si el pluralismo, así entendido, es un valor positivo y constitucional que debe ser aplicado no solo en los centros públicos, sino también, como mínimo, en todos los que reciben fondos públicos, e incluso en los centros privados; es decir, en la enseñanza y análisis — por supuesto, científico-, entre otras cuestiones, de las distintas confesiones, creencias o convicciones ideológicas, religiosas o morales. Esta cuestión, íntimamente conectada con la de las relaciones parental-filiales, la libertad de conciencia y el derecho a una (in)formación plural por parte de los menores, será tratada y desarrollada en la segunda parte de este ensayo.

\section{Nota del autor}

Antonio Viñao Frago es Doctor en Derecho y Profesor Honorario de Teoría e Historia de la Educación de la Universidad de Murcia. Ha sido miembro del Comité Ejecutivo de la International Standing Conference for the History of Education (1996-2000) y presidente de la Sociedad Española de Historia de la Educación (2001-2005), así como director del Centro de Estudios sobre la Memoria Educativa (CEME) de la Universidad de Murcia (2009-2013) y de la revista Historia y Memoria de la Educación (2014-2019).

Sus campos de investigación son la historia de la alfabetización y de la cultura escrita (la lectura y la escritura como prácticas socioculturales), de la escolarización y de la enseñanza secundaria, la historia del currículum (espacios y tiempos escolares, disciplinas), del profesorado (profesionalización, autobiografías y memorias), y de la memoria escolar y el patrimonio histórico-educativo, así como de la relación entre las culturas escolares y las políticas y reformas educativas. Sus últimos libros publicados son Sistemas educativos, culturas escolares y reformas: continuidades y cambios (2002), Escuela para todos. Educación y modernidad en la España del siglo XX (2004), Religión en las aulas: una materia controvertida (2014), School memories. New trends in the history of 
education research (2016), en coedición con Juri Meda y Cristina Yanes, y, en coedición con Pedro Luis Moreno, Imagen y educación. Marketing, comercialización, didáctica (España, siglo XX) (2017).

\section{REFERENCIAS}

Aláez Corral, Benito. «El ideario educativo constitucional como fundamento de la exclusión de la educación diferenciada por razón de sexo de la financiación pública». Revista Española de Derecho Constitucional 86 (2009): 31-64.

Aláez Corral, Benito. «El ideario educativo constitucional como límite a las libertades educativas». Revista Europea de Derechos Fundamentales 17 (2011): 91-129.

Aláez Corral, Benito. "Artículo 27. El derecho a una educación democrática, libre y plural». En Comentario a la Constitución española. 40 aniversario 1978-2018. Tomo I (Preámbulo a artículo 96), dirigido por Pablo Pérez Tremps y Alejandro Saiz Arnáiz y coordinado por Carmen Montesinos Padilla, 601-619. Valencia: Tirant lo Blanch, 2018.

Alzaga Villamil, Óscar. Comentario sistemático a la Constitución española de 1978. Madrid: Ediciones del Foro, 1978.

Arroyo Jiménez, Luis. «Un año de doctrina constitucional». En https://www. academia.edu/38322895/Un_a\%C3\%B1o_de_doctrina_constitucional.

Báez Serrano, Rafael. «Educación diferenciada y conciertos públicos». PhD diss., Universidad de Sevilla, Departamento de Derecho Constitucional, 2015.

Báez Serrano, Rafael. «El ideario educativo de la Constitución española». Iuris Plenum 49 (2016): 111-130.

Báez Serrano, Rafael. «Hacia la consolidación de la constitucionalidad de la educación diferenciada. A propósito de la sentencia del Tribunal Constitucional 31/2018». Revista de Derecho Político 105 (2019): 251-278.

Baylos Grau, Antonio. «El marco constitucional del derecho a la educación: Debates y proyectos en el período constituyente». En El artículo 27 de la Constitución. Cuaderno de quejas, editado por Manuel de Puelles Benítez y Manuel Menor Currás, 77-97. Madrid: Morata, 2018.

Calvo Charro, María. «La libertad de elección de centro docente. Historia de la conculcación de un derecho fundamental». Asamblea: Revista de Parlamentaria de la Asamblea de Madrid 14 (2006): 81-100.

Cámara Villar, Gregorio. "Sobre el concepto y los fines de la educación en la Constitución española». En X Jornadas de Estudio de la Dirección General del Servicio Jurídico del Estado. Introducción a los derechos fundamentales, vol. III, 2159-2191. Madrid: Ministerio de Justicia, 1988. 
Centenera Sánchez-Seco, Fernando. «Educación diferenciada y conciertos educativos: algunas consideraciones a partir de la jurisprudencia del Tribunal Supremo de los últimos años». Anuario de Derecho Eclesiástico del Estado XXX (2014): 767-796.

Cotino Hueso, Lorenzo. «El derecho a la educación». En Lecciones sobre Estado Social y Derechos Sociales, editado por Albert Fernández Noguera y Adoración Guamán Hernández, 415-449. Valencia: Tirant lo Blanch, 2014.

Embid Irujo, Antonio. «Prólogo». Legislación sobre enseñanza. Normas generales, EGB, FP y BUP. Madrid: Tecnos, 1985, 19-44.

Fernández-Miranda Campoamor, Alfonso y Ángel J. Sánchez Navarro. «Artículo 27. Enseñanza». En Comentarios a la Constitución española de 1978. Tomo III. Artículos 24 a 38, dirigido por Óscar Alzaga Villamil, 157-172. Madrid: EDERSA, 1996.

Gallego Díaz, Soledad y Bonifacio de la Cuadra Fernández. «La Constitución». En Memoria de la Transición, coordinada por Joaquín Prieto, Santos Juliá y Javier Pradera, 299-315. Madrid: Taurus, 1996.

González-Varas Ibáñez, Alejandro. «Régimen jurídico de la educación diferenciada en España». Revista General de Derecho Canónico y Derecho Eclesiástico del Estado 31 (2013): 1-27.

Guardia Hernández, Juan José. «Marco constitucional de la enseñanza privada española mantenida con fondos públicos». En https://www.academia.edu/36435006/Marco_constitucional_de_la_ense\%C3\%B1anza_privada_espa $\%$ C3\%B1ola_sostenida_con_fondos_p $\%$ C3\%BAblicos_recorrido_ hist\%C3\%B3rico_y_perspectivas_de_futuro

Martínez López-Muñiz, José Luis; María Calvo Charro, Alejandro González-Varas Muñiz y María Isabel de los Mozos Touyá. Legitimidad de los colegios de un solo sexo y de su derecho a concierto en condiciones de igualdad. Madrid: Iustel, 2015.

De los Mozos Touyá, María Isabel. Educación en libertad y concierto escolar. Madrid: Montecorvo, 1995.

Otero Novas, Manuel. Lo que yo viví. Memorias politicas y reflexiones. Madrid: Editorial Prensa Ibérica, 2015.

Ruiz-Rico Ruiz, Gerardo. «El derecho a la educación en las sentencias del Tribunal Supremo». En Estudios de Derecho Público. Homenaje a Juan José Ruiz-Rico, vol. I, 837-861. Madrid: Tecnos, 1997.

Sánchez Ferlosio, Rafael. Vendrán más años malos y nos harán más ciegos. Barcelona: Círculo de Lectores, 1995.

Vidal Prado, Carlos. El derecho a la educación en España. Bases constitucionales para el acuerdo y cuestiones controvertidas. Madrid: Marcial Pons, 2017.

Viñao, Antonio. «El modelo neoconservador de gobernanza escolar: principios, estrategias y consecuencias en España». En La gobernanza escolar democrática, coordinados por Jordi Collet y Antoni Tort, 41-64. Madrid: Morata 2016. 